\title{
Tryptophan Catabolism to Serotonin and Kynurenine in Women Undergoing in-vitro Fertilization
}

\author{
József BÓDIS ${ }^{1}$, Endre SULYOK ${ }^{3}$, Miklós KOPPÁN ${ }^{1,2}$, Ákos VÁRNAGY ${ }^{2}$, Viktória \\ PRÉMUSZ $^{1,3}$, Krisztina GÖDÖNY ${ }^{1,2}$, Wolfgang RASCHER ${ }^{4}$, Manfred RAUH $^{4}$ \\ ${ }^{1}$ MTA-PTE Human Reproduction Scientific Research Group, University of Pécs, Pécs, Hungary, \\ ${ }^{2}$ Department of Obstetrics and Gynaecology, Medical School, University of Pécs, Pécs, Hungary, \\ ${ }^{3}$ Doctoral School of Health Sciences, Faculty of Health Sciences, University of Pécs, Pécs, \\ Hungary, ${ }^{4}$ Department of Pediatrics and Adolescent Medicine, Hospital and Friedrich-Alexander- \\ University of Erlangen-Nürnberg, Nürnberg, Germany
}

Received January 14, 2020

Accepted September 7, 2020

Epub Ahead of Print November 2, 2020

\section{Summary}

This cross-sectional clinical study was designed to explore the impact of tryptophan-kynurenine and tryptophan-serotonin (5-HT) pathways on reproductive performance during in vitro fertilization (IVF). Paired serum and follicular fluid (FF) samples were obtained from 64 consecutive IVF patients. The analysis was done by using LC-MS/MS. Ovarian hyperstimulation resulted in decreased serum tryptophan $(p<0.004), 5-\mathrm{HT}(p<0.049)$ and kynurenine $(p<0.001)$. FF levels of tryptophan $(R=0.245$, $p<0.051)$, kynurenine $(R=0.556, p<0.001)$ and $5-H T(R=0.523$, $\mathrm{p}<0.001)$ were positively related to their respective serum levels. Clinical pregnancy was associated with higher serum 5-HT $(p<0.045)$ and FF 5-HT $(p<0.020)$ and lower kynurenine to 5-HT ratio $(p<0.024)$. Chemical pregnancy was also positively related to FF $5-\mathrm{HT}(\mathrm{R}=0.362, \mathrm{p}<0.024)$. Moreover, there was a direct relationship of the number of mature oocytes to the FF $5-\mathrm{HT}$ $(R=0.363, p<0.020)$ but it was inversely related to FF tryptophan to $5-\mathrm{HT}$ and FF kynurenine to $5-\mathrm{HT}$ ratios $(\mathrm{R}=-0.389, \mathrm{p}<0.016$ and $\mathrm{R}=-0.337, \mathrm{p}<0.036$, respectively). Multivariate logistic regression revealed that the number of mature oocytes was significantly influenced by FF $5-\mathrm{HT}(\beta=0.473, p<0.001)$. In IVF patients ovarian hyperstimulation results in a reduction of the availability of tryptophan to catabolic pathways to kynurenine and 5-HT. Outcome measures improved significantly when 5-HT predominated over kynurenine.

\section{Key words}

in vitro Fertilization - Tryptophan • Kynurenine • Serotonin • Oocyte maturation

\section{Corresponding author}

Ákos Várnagy, Department of Obstetrics and Gynaecology, Medical School, University of Pécs, Pécs, Hungary. E-mail: varnagy.akos@pte.hu

\section{Introduction}

The essential amino acid tryptophan acts as a precursor to various metabolic pathways that result in the production of proteins, serotonin (5-HT) and kynurenines. The major non-protein route for oxidative degradation of tryptophan (95\%) is the formation of kynurenine and downstream metabolites, collectively referred to as kynurenines. (Fig. 1) These biologically active compounds have been shown to be implicated in several conditions including pregnancy-related immune tolerance and inflammatory disorders (Wolf et al. 1970, Chen and Guillemin 2009, Stone et al. 2013).

Two enzymes initiate tryptophan catabolism; the hepatic tryptophan-2,3-dioxygenase (TDO) that is induced by glucocorticoids and tryptophan and inhibited by progesterone and estrogen, as well as the indoleamine2,3-dioxygenase (IDO) which is present in a variety of cell types including macrophages and monocytes. It is up-regulated by certain cytokines and inflammatory molecules, but its most potent stimulant is interferon gamma (IFN- $\gamma$ ) (Sainio et al. 1996, Badawy 2015). Tryptophan depletion has anti-proliferative and apoptotic 


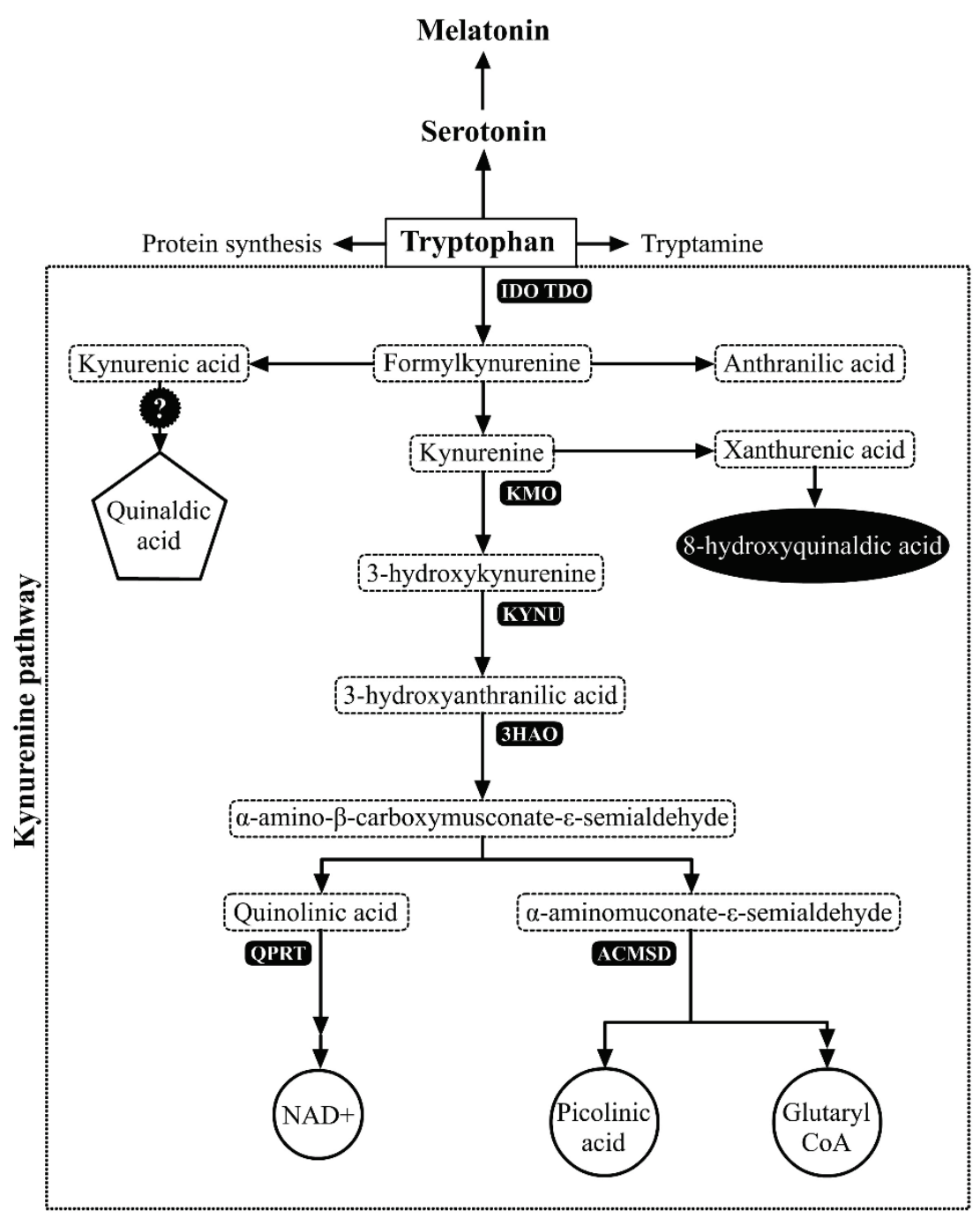

Fig. 1. Tryptophan catabolism with particular reference to the kynurenine pathway.

Abbreviations of the key enzymes involved in the kynurenine pathway:

IDO: Indoleamine 2,3 - dioxygenase

TDO: Tryptophane 2,3 - dioxygenase KYNU: Kynureninase

KATs: Kynurenine aminotransferases

KMO: Kynurenine 3-monooxygenase

3HAO: 3-hydroxyanthranilic acid oxygennase

ACMSD: Aminocarboxymuconate-semialdehyde decarboxylase

QPRT: Quinolinic acid phosphoribosyltransferase

effect on T-cells (Munn et al. 1998, Munn et al. 1999, Lee et al. 2002). The low tryptophan levels are accompanied by elevation of kynurenines and by a subsequent reduction of 5-HT synthesis (Wichers et al. 2005).

In this regard it is to be stressed that serotoninergic regulation of the hypothalamic-pituitarygonadal axis has been established and evidence has been provided for the role of 5-HT in female reproduction, particularly in the local intraovarian regulation (Kiss and Halasz 1985, Bodis et al. 1993, Li and Pelletier 1995, Hery et al. 1997). It is conceivable, therefore, that the activation of the tryptophan-kynurenine pathway and the simultaneous decrease of tryptophan bioavailability for 5-HT synthesis may have negative impact on reproductive performance. In support of this possibility the presence of tryptophan hydroxylase (the enzyme for 5-HT synthesis), 5-HT, its receptor and the 5-HT transporter has been documented in oocytes and preimplantation embryos suggesting that the paracrine/autocrine serotoninergic networks are functional already in the earliest embryonic development (Vesela

et al. 2003, Il'kova et al. 2004, Amireault and Dube 2005a, Amireault and Dube 2005b).

In addition to 5-HT, kynurenines have also been demonstrated to be essential elements of reproduction by providing immune protection for implantation and for embryonic/fetal development (Mellor and Munn 2001, Kudo et al. 2004a, Groebner et al. 2011a, Grozdics et al. 2014, Badawy 2015).

On the basis of these observations it is relevant to assume that the production of 5-HT and kynurenines should be kept in balance and the shift of tryptophan catabolism either to 5-HT or to kynurenine pathway may compromise the success rate of fertilization.

The possible involvement of major metabolic hormones including insulin, leptin, adiponectin, resistin and ghrelin in the control of tryptophan catabolism, ovarian function and fertilization outcome has also been studied in IVF patients (Le Floc' et al. 2011, Várnagy et al. 2013, Dafopoulos et al. 2016). Their conflicting 
results, however, warrant further studies to draw definitive conclusion on the diagnostic and/or therapeutic potential of these hormones in endocrine, - paracrine, - or autocrine regulation of ovarian function.

In order to get information about the role of tryptophan metabolism in women undergoing in vitro fertilization (IVF) the present study was designed a) to explore the response pattern of tryptophan, 5-HT and kynurenine to ovarian hyperstimulation, b) to assess the relationship between serum and follicular fluid (FF) levels of these hormones c) to establish the effects of 5-HT and kynurenine individually or in combination on reproductive performance (number of mature oocytes and embryos, chemical and clinical pregnancy) and d) to analyse the data of women with endometriosis separately as these patients are at particularly high risk for IVF failure.

\section{Methods}

\section{Patients}

This single centre, cross-sectional clinical study was performed between September 1 and October 1, 2015 and September 1 and November 12018 in the Assisted Reproduction Unit, Department of Obstetrics and Gynaecology, University of Pécs, Hungary. In these periods we started 64 unselected IVF cycles and made transvaginal ultrasound-guided aspiration of FF. The clinical parameters of the patients are given in Table 1.

All patients were on normal, unrestricted diet, neither of them had metabolic, - endocrine, cardiovascular, - renal, - or psychiatric diseases so they did not receive drug therapy that might interfere with tryptophan metabolism.

The study was reviewed and approved by the Human Reproduction Committee of the Hungarian Medical Research Council (5273-2/2012/EHR). Signed informed consent was obtained from all patients who participated in the study. The investigation conforms to the principles outlined in the Declaration of Helsinki.

\section{Protocols}

The protocol of controlled ovarian hyperstimulation, the collection of serum and follicular fluid and fertilization were presented in our previous publication (Várnagy et al. 2018).

\section{Laboratory measurements}

The analysis of tryptophan, kynurenine, and
Table 1. Clinical characteristics of the patients studied

\begin{tabular}{|c|c|}
\hline Characteristics & $n=64$ \\
\hline Age - yr & $34.9 \pm 5.0$ \\
\hline Nulligravid - $n(\%)$ & $55(85.9)$ \\
\hline Nulliparous - $n(\%)$ & $53(82.8)$ \\
\hline Duration of infertility - yr & $3.9 \pm 2.3$ \\
\hline Body-mass index $-\mathrm{kg} / \mathrm{m}^{2}$ & $22.9 \pm 2.9$ \\
\hline \multicolumn{2}{|l|}{ Cause of infertility - n (\%) } \\
\hline Poor semen quality & $22(34.4)$ \\
\hline Tubal & $16(25.0)$ \\
\hline Endometriosis & $18(28.1)$ \\
\hline Other female & $4(6.3)$ \\
\hline Combined male-female & $1(1.6)$ \\
\hline Unexplained & $3(4.7)$ \\
\hline \multicolumn{2}{|c|}{ No. of stimulation procedures initiated before } \\
\hline Cycle 0 & 31 \\
\hline Cycle 1 & 16 \\
\hline Cycle 2 & 7 \\
\hline Cycle 3 & 7 \\
\hline Cycle 4 & 3 \\
\hline Serum estradiol - pmol/l & $2593.3 \pm 3913.3$ \\
\hline Total dose of gonadotropin - IU & $2012.8 \pm 621.4$ \\
\hline Duration of stimulation - days & $11.2 \pm 2.8$ \\
\hline No. of matured oocytes (metaphasis II) & $6.33 \pm 4.72$ \\
\hline No. of Grade 1 embryos & $3.50 \pm 2.64$ \\
\hline $\begin{array}{l}\text { No. of transferred embryos (fresh } \\
\text { only) }\end{array}$ & $1.6 \pm 0.8$ \\
\hline hCG on day $12-I U$ & $318.4 \pm 715.2$ \\
\hline No. of chemical pregnancies - $n(\%)$ & $19(29.7)$ \\
\hline No. of clinical pregnancies - $n(\%)$ & $18(28.1)$ \\
\hline
\end{tabular}

5-HT is based on phenylisothyocyanate (PITC) derivation in the presence of isotope labelled internal standards using liquid chromatography-mass spectrometry/mass spectrometry (LC-MS/MS) in the multiple reaction monitoring detection mode (tryptophan-d8 348.2/195.2, tryptophan $340.2 / 188.2$, kynurenine-d6 $350.2 / 151.2$, kynurenine $344.2 / 146.2$, d4-serotonin 316.3/164.2, serotonin 312.3/160.2). The method allows the simultaneous quantification using a 4000 QTrap mass spectrometer (SCIEX, Darmstadt, Germany) with electrospray ionization. The HPLC system consisted of a Shimadzu CBM-20A command module, two LC-20AD pumps, and a Shimadzu SIL-20AC-HT autosampler. 


\section{Statistical analysis}

Statistical analyses were performed using the 22.0 software of the SPSS (SPSS Inc., Chicago, IL, USA). Normality of data distribution was tested by Kolmogorov-Smirnov test. Depending on distribution Student t-test or Mann-Whitney U-test were used to compare continuous variables. The association between two continuous variables was tested by using Spearman's or Pearson's correlation coefficients. Multiple linear or logistic regression models were used to identify the variables independently associated with IVF outcome parameters (number of oocytes, number of embryos, chemical/clinical pregnancy). Data were expressed as median, $25-75 \%$ quartiles and a value of $p<0.05$ was considered statistically significant.

\section{Results}

Table 2 shows serum and FF levels of tryptophan, 5-HT and kynurenine in the whole patient population who underwent IVF and separately in the non-pregnant and pregnant groups. It can be seen that in response to ovarian hyperstimulation there was a significant decrease in serum tryptophan $[56.71(50.33 ; 65.98)$ vs. $50.18(45.60 ; 57.94) \mu \mathrm{mol} / \mathrm{l}$, $\mathrm{p} \leq 0.001]$ kynurenine $[1.72(1.35 ; 2.29)$ vs. $1.43(1.19$; 1.71) $\mu \mathrm{mol} / 1, \mathrm{p} \leq 0.001]$, and serum 5 -HT $[0.70(0.56 ; 1.02)$ vs. $0.65(0.42 ; 0.83) \mu \mathrm{mol} / \mathrm{l}, \mathrm{p}=0.049]$. FF levels of tryptophan $[39.30(33.23 ; 48.74) \mu \mathrm{mol} / \mathrm{l}, \mathrm{p} \leq 0.001]$ and 5-HT [0.04 (0.02;0.10) $\mu \mathrm{mol} / 1, \mathrm{p} \leq 0.001]$ were markedly depressed, while FF kynurenine remained unchanged $[1.50(1.33 ; 1.81) \mu \mathrm{mol} / 1]$ when compared with their corresponding serum levels obtained at the time of oocyte retrieval. As a consequence, the serum tryptophan to kynurenine ratio increased significantly $(\mathrm{p}=0.011)$, whereas the rise in the serum tryptophan to $5-\mathrm{HT}$ and kynurenine to 5-HT ratios did not reach statistical significance. In $\mathrm{FF}$ the tryptophan to kynurenine ratio decreased significantly $(p \leq 0.001)$, however, the tryptophan to 5 -HT $(\mathrm{p} \leq 0.001)$ and kynurenine to $5-\mathrm{HT}$ ratios $(p \leq 0.001)$ proved to be markedly elevated. These changes in the derived ratios are indicative of a shift of tryptophan catabolism from 5-HT to kynurenine, particularly within the ovaries.

When patients who underwent successful IVF treatment and progressed to clinical pregnancy and delivery at term were compared with those who failed to become pregnant similar response pattern was seen after hyperstimulation in each serum and FF tryptophan, kynurenine and 5-HT. It is of note, however, that the pregnancy positive patients had significantly higher serum $(p=0.045)$, and FF $(p=0.020) 5$-HT levels and a marked reduction in the kynurenine to 5-HT ratio $(p=0.024)$, as compared to the pregnancy negative patients. These findings suggest that pregnancy is associated with the diversion of tryptophan catabolism from kynurenine to 5-HT pathway.

Significant positive correlations were seen between serum and FF levels for 5-HT $(\mathrm{R}=0.523$, $\mathrm{p} \leq 0.001)$ and kynurenine $(\mathrm{R}=0.556, \mathrm{p} \leq 0.001)$ but not for tryptophan $(\mathrm{R}=0.244, \mathrm{p}=0.061)$ indicating that 5 -HT and kynurenine mainly originate from the maternal circulation, therefore, their local ovarian production might be quite limited.

Univariate regression analysis of hormonal interactions revealed that tryptophan was significantly related to 5 -HT $(\mathrm{R}=0.390, \mathrm{p}=0.002)$ but not to kynurenine. Furthermore, 5-HT was inversely related to tryptophan to 5-HT $(\mathrm{R}=-0.898, \mathrm{p} \leq 0.001)$ and kynurenine to 5 -HT $(\mathrm{R}=-0.773, \mathrm{p} \leq 0.001)$ ratios, whereas kynurenine was negatively associated with tryptophan to kynurenine ( $\mathrm{R}=-0.687, \mathrm{p} \leq 0.001)$ but positively with kynurenine to 5-HT ratios $(\mathrm{R}=0.640, \mathrm{p} \leq 0.001)$.

Table 3 demonstrates the association of selected clinical and hormone parameters with the products of tryptophan catabolism. It is apparent that the age of the patients had negative impact on FF tryptophan $(\mathrm{R}=-0.270, \mathrm{p}=0.037)$ and $\mathrm{FF}$ 5-HT $(\mathrm{R}=-0.494, \mathrm{p}=0.001)$, and $\mathrm{FF}$ tryptophan to kynurenine ratio $(\mathrm{R}=-0.270$, $\mathrm{p}=0.037$ ), while positively affected $\mathrm{FF}$ ratios of tryptophan to 5 - $\mathrm{HT}(\mathrm{R}=0.465, \mathrm{p}=0.003)$ and kynurenine to 5 -HT $(\mathrm{R}=0.382, \mathrm{p}=0.005)$. Serum and FF levels of kynurenine remained unaffected by age. Moreover, estradiol levels were positively related to serum tryptophan $(\mathrm{R}=0.281, \mathrm{p}=0025)$ whereas there was an inverse relationship between FSH dosage and FF tryptophan $(\mathrm{R}=-0.310, \mathrm{p}=0.013)$. All parameters measured remained unaffected by the number of IVF cycles.

Importantly, the number of mature oocytes was positively related to FF 5 -HT $(\mathrm{R}=0.363, \mathrm{p}=0.020)$ and inversely to FF tryptophan to 5-HT and FF kynurenine to 5-HT ratios $(\mathrm{R}=-0.389, \mathrm{p}=0.016$ and $\mathrm{R}=-0.337, \mathrm{p}=0.036$, respectively). FF 5-HT was also positively associated with serum hCG levels taken on day 12 that is considered as an index of chemical pregnancy $(\mathrm{R}=0.362 \mathrm{p}=0.024)$. Using multivariate logistic regression analysis correction was made for potential confounders and only the number 


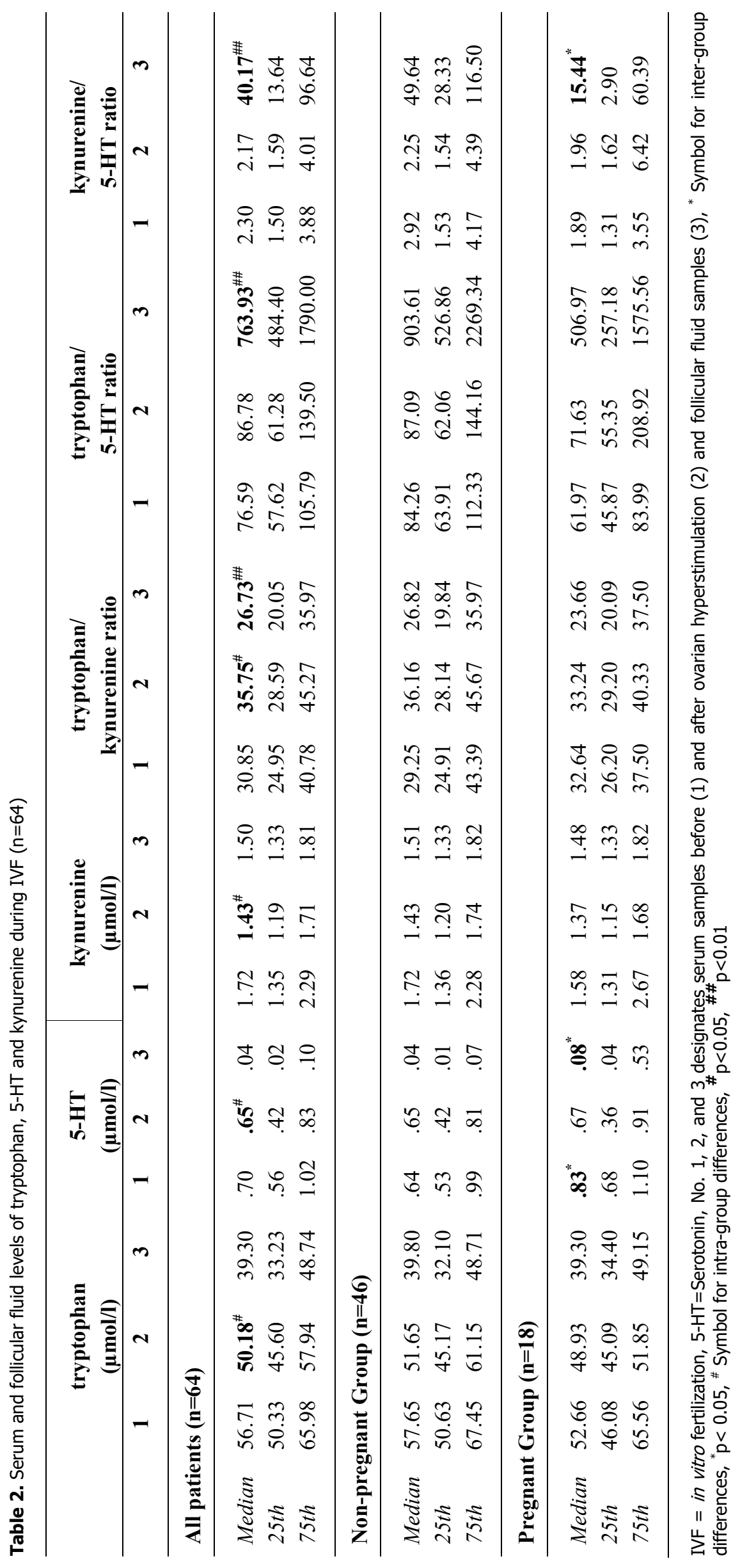




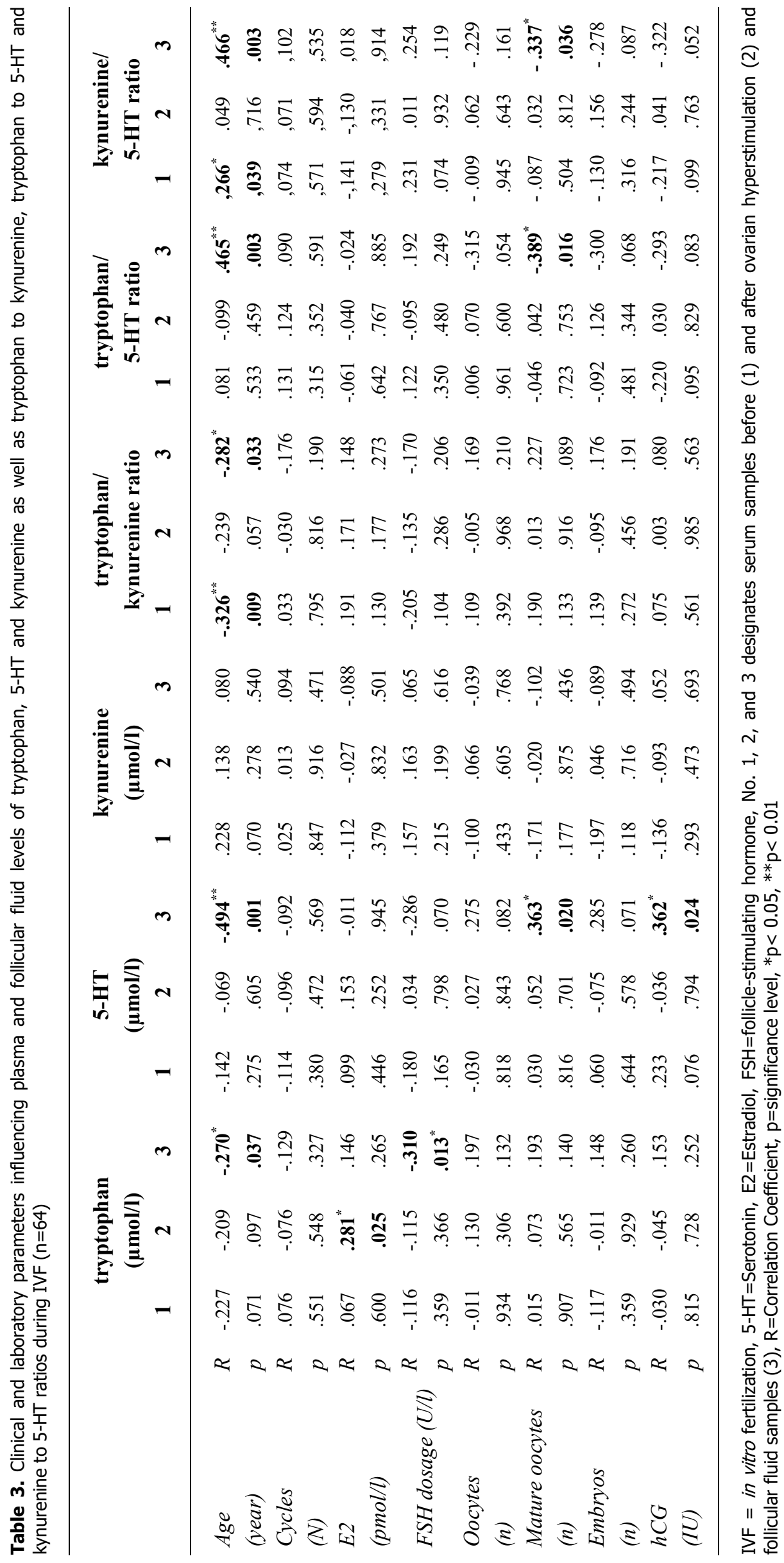




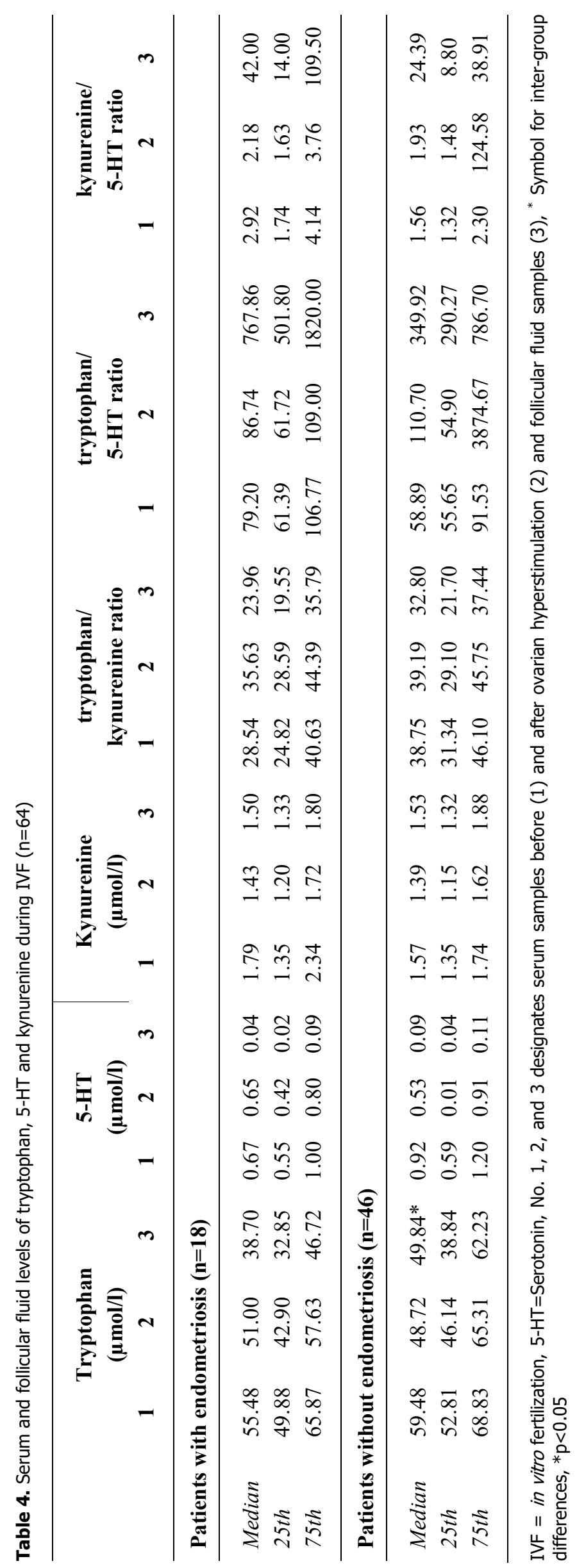


of mature oocytes as dependent variable was significantly influenced by serum estradiol $(\beta=0.352, p=0.013)$ and FF 5-HT $(\beta=0.473, p \leq 0.001)$. It is of note, that all of the outcome measures we investigated proved to be independent of serum and FF tryptophan and kynurenine.

When patients with endometriosis were considered as a separate group and their results were compared with those of the rest of the patients FF tryptophan was markedly depressed in the endometriosis group $[38.70(32.85 ; 46.72)$ vs. 49.84 $(38.84 ; 62.23) \mathrm{p}=0.023]$. No significant differences could be found between the two groups in the other indices of tryptophan catabolism (Table 4). The major clinical characteristics and outcome measures proved also to be similar.

\section{Discussion}

Our study demonstrated that in patients undergoing IVF serum tryptophan, kynurenine and 5-HT decreased significantly in response to controlled ovarian hyperstimulation indicating a reduction of tryptophan bioavailability for catabolism to 5-HT and to kynurenine. All these compounds could be detected in FF and were closely related to their respective serum levels suggesting that FF tryptophan, 5-HT and kynurenine mainly derive from the maternal circulation rather than from local ovarian production. Clinical pregnancy was associated with higher serum and FF 5-HT and lower kynurenine to 5-HT ratio, while chemical pregnancy was positively related to FF 5-HT. Moreover, there was a direct relationship of mature oocytes to FF 5-HT but it was inversely related to the FF tryptophan to 5-HT and to FF kynurenine to 5-HT ratios. These findings indicate that in our clinical setting both the tryptophan-kynurenine and the tryprophan-5-HT pathways are activated but there is a shift from kynurenine to 5-HT when successful pregnancy is achieved.

To our knowledge no studies have been performed to investigate simultaneously the function of tryptophan-kynurenine and tryptophan-5-HT pathways in women undergoing IVF. However, convincing evidence has been provided for the essential role of tryptophan catabolism to both 5-HT and kynurenine in implantation, early embryonic and fetal development. With this contention in line embryo viability has been shown to be enhanced through 5-HT signalling (Doherty et al. 2011) with the possible contribution of embryonal, placental and maternal 5-HT (Cote et al. 2007, Bonnin and Levitt 2012). The contribution of multifunctional 5-HT to the maturation and differentiation of oocytes had already been reviewed by Buznikov et al. (1996). On the other hand, TDO, IDO and subsequent enzymes of kynurenine pathway have been identified in placenta, decidua and in early conceptus (Suzuki et al. 2001, Kudo et al. 2004a, Kudo et al. 2004b, Ligam et al. 2005, Manuelpillai et al. 2005).

The interdependence of tryptophan-5-HT and tryptophan-kynurenine metabolic pathways during the peri-implantation period is supported by the observations of Groebner et al. (2011a). They reported that in bovine pregnancy the endometrium had increased IDO mRNA expression and elevated tissue kynurenine concentrations but markedly reduced 1-tryptophan and 5-HT. These findings are suggestive of a shift to the kynurenine pathway which resulted in decreased number of CD45-positive leukocytes and provided a possible immunological mechanism to establish embryo tolerance in early pregnancy (Groebner et al. 2011a).

However, the immune protection of the embryo by kynurenine is a matter of debate. Maternal cytokine profile in the first trimester of pregnancy is characterized by the increase of growth factors and by the predominance of anti-inflammatory cytokines. The absence of inflammatory environment, therefore, does not require immunosuppression by kynurenines (Hannan et al. 2014, Holtan et al. 2015, Yue et al. 2015). The elevated tryptophan levels at this stage of pregnancy may be accounted for by progesterone and estrogen inhibition of TDO, rather than the low expression of functional IDO (Badawy 1988, Ftukijwatari et al. 2004, Ligam et al. 2005). The excess tryptophan in early pregnancy has been claimed to serve as a substrate for protein and 5-HT synthesis. As pregnancy progresses tryptophan availability is maintained, IDO expression is up-regulated and immunosuppressive kynurenines are generated (Schrocksnadel et al. 1996).

The involvement of kynurenines in the control of embryonic/fetal development is further substantiated by demonstrating that IDO inhibition with 1-methyltryptophan or deletion of IDO gene cause pregnancy complications and fetal compromise (Munn et al. 1998, Santillan et al. 2015). Additionally, prenatal inhibition of the conversion of kynurenine to kynurenic acid alters developmentally relevant processes including synaptic plasticity and protein expression in the rat hippocampus (Forrest et al. 2013).

It is also to be considered that placental enzymes generating kynurenine (IDO, TDO) can clean free radicals (Britan et al. 2006) and some kynurenine pathway metabolites have also been shown to effectively remove reactive oxygen species (Christen et al. 1990, Weiss et al. 2002). Consistent with these observations phosphorylated tryptophan and its catabolism to kynurenine may activate nuclear factors that mediate the expression of antioxidant proteins and may provide 
protection against free radical damage thereby improving redox status and reproductive performance ( $\mathrm{Xu}$ et al. 2018). The tryptophan/kynurenine-related enhanced oxidative defence appears to be of particular importance in endometriosis where oxidative stress prevails (Fabjan et al. 2018, Várnagy et al. 2018). In our patients with endometriosis, however, adaptive activation of this antioxidant system could not be observed.

In our IVF patients we failed to document the activation of tryptophan-kynurenine pathway over the trypophan-5-HT pathway and to provide evidence for the protective role of kynurenine or its downstream metabolites. The reason for our failure is not apparent, further studies using molecular biology approach are to be conducted to reveal the complex interactions of the relevant clinical, endocrine and metabolic factors.

The association between the developmental potential of preimplantation embryo and amino acid metabolism has been the matter of intensive research and exogenous amino acid supply has been proposed to enhance embryo viability (Groebner et al. 2011b, Drábková et al. 2016). In view of the ovarian hyperstimulation - induced reduction in maternal serum tryptophan and the shift of tryptophan catabolism from the kynurenine to 5-HT pathway it is tempting to suggest that dietary tryptophan supplement to the mothers may improve the IVF outcome. It is to be considered, however, that most dietary tryptophan $(>95 \%)$ is metabolised via kynurenine pathway and only a small fraction $(<5 \%)$ of ingested tryptophan is available for 5-HT synthesis (Wolf 1974). Although, some of the downstream metabolites of kynurenine have beneficial, curative properties, others proved to be toxic and increase oxidative stress (quinolinic acid, 3-hydroxykynurenine, 3-hydroxy-anthranilic acid, picolinic acid) (Le Floc', Otten and Merlot 2011, Sainio et al. 1996). With respect to these controversies excess tryptophan intake is not recommended until its mechanisms of action, efficiency and safety is not clearly established.

In conclusion, adequate tryptophan supply for the generation of 5-HT and kynurenines is essential for the success of reproduction. We assume that this holds true for IVF, although only 5-HT but not kynurenine in maternal sera and FF were associated with the number of oocytes and chemical or clinical pregnancies. These observations support the notion that the tryptophan- 5-HT pathway prevails over the tryptophan-kynurenine pathway when chemical/clinical pregnancy is achieved.

\section{Study limitations}

We included IVF patients with heterogeneous infertility diagnosis, therefore the selection bias cannot be excluded. Furthermore, there are several important metabolites along the kynurenine pathway that compose a network of interrelated bioactive compounds, so the measurement of the precursor kynurenine alone does not allow to explore the impact of the whole system on the IVF process.

\section{Conflict of Interest}

There is no conflict of interest.

\section{Acknowledgements}

We want to thank women who underwent IVF treatment at the Assisted Reproduction Unit, Department of Obstetrics and Gynaecology, University of Pécs, for participating in our study. This work was supported by the National Laboratory on Reproduction as part of the "Establishment of National Laboratories 2020" program and by GINOP-2.3.2-15-2016-00021 ("The use of chiptechnology in increasing the effectiveness of human in vitro fertilization"). The funding sources did not have any role in the study design; in collection, analysis and interpretation of data, or in writing and submitting this manuscript.

\section{References}

AMIREAULT P and DUBE F: Intracellular cAMP and calcium signaling by serotonin in mouse cumulus-oocyte complexes. Mol Pharmacol 68: 1678-1687, 2005. https://doi.org/10.1124/mol.104.010124

AMIREAULT P, DUBE F: Serotonin and its antidepressant-sensitive transport in mouse cumulus-oocyte complexes and early embryos. Biol Reprod 73: 358-365, 2005. https://doi.org/10.1095/biolreprod.104.039313

BADAWY AA: Effects of pregnancy on tryptophan metabolism and disposition in the rat. Biochem J 255: 369-372, 1988.

BADAWY AA: Tryptophan metabolism, disposition and utilization in pregnancy. Biosci Rep 35, 2015. https://doi.org/10.1042/BSR20150197

BODIS J, TOROK A, TINNEBERG HR, HANF V, PAPENFUSS F SCHWARZ H: Serotonin induces progesterone release from human granulosa cells in a superfused granulosa cell system. Arch Gynecol Obstet 253: 59-64, 1993. https://doi.org/10.1007/BF02768730 
BONNIN A, LEVITT P: Placental Source for 5-HT that tunes fetal brain development. Neuropsychopharmacology 37 : 299-300, 2012. https://doi.org/10.1038/npp.2011.194

BRITAN A, MAFFRE V, TONE S, DREVET JR: Quantitative and spatial differences in the expression of tryptophanmetabolizing enzymes in mouse epididymis. Cell Tissue Res 324: 301-310, 2006. https://doi.org/10.1007/s00441-005-0151-7

BUZNIKOV GA, SHMUKLER YB, LAUDER JM: From oocyte to neuron: do neurotransmitters function in the same way throughout development? Cell Mol Neurobiol 16: 537-559, 1996. https://doi.org/10.1007/BF02152056

CHEN Y and GUILLEMIN GJ: Kynurenine pathway metabolites in humans: disease and healthy states. Int J Tryptophan Res 2: 1-19, 2009. https://doi.org/10.4137/IJTR.S2097

CHRISTEN S, PETERHANS E, STOCKER R: Antioxidant activities of some tryptophan metabolites: possible implication for inflammatory diseases. Proc Natl Acad Sci 87: 2506-2510, 1990. https://doi.org/10.1073/pnas.87.7.2506

COTE F, FLIGNY C, BAYARD E, LAUNAY JM, GERSHON MD, MALLET J, VODJDANI G: Maternal serotonin is crucial for murine embryonic development. Proc Natl Acad Sci 104: 329-334, 2007. https://doi.org/10.1073/pnas.0606722104

DAFOPOULOS K, MESSINI CI, ANIFANDIS G, GEORGOULIAS P, SOURLAS D, MESSINIS IE: Blood ghrelin, adiponectin and resistin levels during controlled ovarian stimulation in IVF cycles. Physiol Res 65: 809-814, 2016. https://doi.org/10.33549/physiolres.933295

DOHERTY LF, KWON HE, TAYLOR HS: Regulation of tryptophan 2,3-dioxygenase by HOXA10 enhances embryo viability through serotonin signaling. Am J Physiol Endocrinol Metab 300: E86-93, 2011. https://doi.org/10.1152/ajpendo.00439.2010

DRÁBKOVÁ P, ANDRLOVÁ L, HAMPL R, KANĎÁR R: Amino acid metabolism in human embryos. Physiol Res 65: 823-832, 2016. https://doi.org/10.33549/physiolres.933240

FABJAN T, EVRTAČNIK-BOKAL E, KUMER K, OSREDKAR J: Determination of oxidative stress balance in follicular fluid. J Lab Med 42: 51-58, 2018. https://doi.org/10.1515/labmed-2017-0106

FORREST CM, KHALIL OS, PISAR M, DARLINGTON LG, STONE TW: Prenatal inhibition of the tryptophankynurenine pathway alters synaptic plasticity and protein expression in the rat hippocampus. Brain Res 1504: 1-15, 2013. https://doi.org/10.1016/j.brainres.2013.01.031

FTUKIJWATARI T, MURAKAMI M, OHTA M, KIMURA N, JIN-NO Y, SASAKI R, SHIBATA K: Changes in the urinary excretion of the metabolites of the tryptophan-niacin pathway during pregnancy in Japanese women and rats. J Nutr Sci Vitaminol 50: 392-398, 2004. https://doi.org/10.3177/jnsv.50.392

GROEBNER AE, SCHULKE K, SCHEFOLD JC, FUSCH G, SINOWATZ F, REICHENBACH HD, WOLF E, MEYER HH, ULBRICH SE: Immunological mechanisms to establish embryo tolerance in early bovine pregnancy. Reprod Fertil Dev 23: 619-632, 2011a. https://doi.org/10.1071/RD10230

GROEBNER AE, RUBIO-ALIAGA I, SCHULKE K, REICHENBACH HD, DANIEL H, WOLF E, MEYER HH, ULBRICH SE: Increase of essential amino acids in the bovine uterine lumen during preimplantation development. Reproduction 141:685-695, 2011b. https://doi.org/10.1071/RD10230

GROZDICS E, BERTA L, BAJNOK A, VERES G, ILISZ I, KLIVENYI P, RIGO J JR, VECSEI L, TULASSAY T TOLDI G: B7 costimulation and intracellular indoleamine-2,3-dioxygenase (IDO) expression in peripheral blood of healthy pregnant and non-pregnant women. BMC Pregnancy Childbirth 14(306):1-9, 2014. https://doi.org/10.1186/1471-2393-14-306

HANNAN NJ, BAMBANG K, KAITU'U-LINO TJ, KONJE JC, TONG S: A bioplex analysis of cytokines and chemokines in first trimester maternal plasma to screen for predictors of miscarriage. PLoS ONE 9: e93320, 2014. https://doi.org/10.1371/journal.pone.0093320

HERY M, FRANCOIS-BELLAN AM, HERY F, DEPREZ P, BECQUET D: Serotonin directly stimulates luteinizing hormone-releasing hormone release from GT1 cells via 5-HT7 receptors. Endocrine 7: 261-265, 1997. https://doi.org/10.1007/BF02778149 
HOLTAN SG, CHEN Y, KAIMAL R, CREEDON DJ, ENNINGA EAL, NEVALA WK, MARKOVIC SN: Growth modelling of the maternal cytokine milieu throughout normal pregnancy: macrophage-derived chemokine decreases as inflammation/counterregulation increases. J Immunol Res 2015: 1-11, 2015. https://doi.org/10.1155/2015/952571

IL'KOVA G, REHAK P, VESELA J, CIKOS S, FABIAN D, CZIKKOVA S, KOPPEL J: Serotonin localization and its functional significance during mouse preimplantation embryo development. Zygote 12: 205-213, 2004. https://doi.org/10.1017/S0967199404002862

KISS J, HALASZ B: Demonstration of serotoninergic axons terminating on luteinizing hormone-releasing hormone neurons in the preoptic area of the rat using a combination of immunocytochemistry and high resolution autoradiography. Neuroscience 14: 69-78, 1985. https://doi.org/10.1016/0306-4522(85)90164-2

KUDO Y, BOYD CA, SPYROPOULOU I, REDMAN CW, TAKIKAWA O, KATSUKI T, HARA T, OHAMA K, SARGENT IL: Indoleamine 2,3-dioxygenase: distribution and function in the developing human placenta. J Reprod Immunol 61: 87-98, 2004a. https://doi.org/10.1016/j.jri.2003.11.004

KUDO Y, HARA T, KATSUKI T, TOYOFUKU A, KATSURA Y, TAKIKAWA O, FUJII T, OHAMA K: Mechanisms regulating the expression of indoleamine 2,3-dioxygenase during decidualization of human endometrium. Hum Reprod 19: 1222-1230, 2004b. https://doi.org/10.1093/humrep/deh218

LEE GK, PARK HJ, MACLEOD M, CHANDLER P, MUNN DH, MELLOR AL: Tryptophan deprivation sensitizes activated $\mathrm{T}$ cells to apoptosis prior to cell division. Immunology 107: 452-460, 2002. https://doi.org/10.1046/j.1365-2567.2002.01526.x

LE FLOC'H N, OTTEN W, MERLOT E: Tryptophan metabolism, from nutrition to potential therapeutic application. Amino Acids 41: 1195-1205, 2011. https://doi.org/10.1007/s00726-010-0752-7

LI S, PELLETIER G: Involvement of serotonin in the regulation of GnRH gene expression in the male rat brain. Neuropeptides 29: 21-25, 1995.https://doi.org/10.1016/0143-4179(95)90052-7

LIGAM P, MANUELPILLAI U, WALLACE EM, WALKER D: Localisation of indoleamine 2,3-dioxygenase and kynurenine hydroxylase in the human placenta and decidua: implications for role of the kynurenine pathway in pregnancy. Placenta 26: 498-504, 2005. https://doi.org/10.1016/j.placenta.2004.08.009

MANUELPILLAI U, LIGAM P, SMYTHE G, WALLACE EM, HIRST J, WALKER DW: Identification of kynurenine pathway enzyme mRNAs and metabolites in human placenta: up-regulation by inflammatory stimuli and with clinical infection. Am J Obstet Gynecol 192: 280-288, 2005. https://doi.org/10.1016/j.ajog.2004.06.090

MELLOR AL and MUNN DH: Tryptophan catabolism prevents maternal $\mathrm{T}$ cells from activating lethal anti-fetal immune responses. J Reprod Immunol 52: 5-13, 2001. https://doi.org/10.1016/S0165-0378(01)00118-8

MUNN DH, SHAFIZADEH E, ATTWOOD JT, BONDAREV I, PASHINE A, MELLOR AL: Inhibition of T Cell Proliferation by Macrophage Tryptophan Catabolism. J Exp Med 189: 1363-1372, 1999. https://doi.org/10.1084/jem.189.9.1363

MUNN DH, ZHOU M, ATTWOOD JT, BONDAREV I, CONWAY SJ, MARSHALL B, BROWN C, MELLOR AL: Prevention of allogeneic fetal rejection by tryptophan catabolism. Science 281: 1191-1193, 1998. https://doi.org/10.1126/science.281.5380.1191

SAINIO EL, PULKKI K, YOUNG SN: L-tryptophan: biochemical, nutritional and pharmacological aspects. Amino Acids 10: 21-47, 1996. https://doi.org/10.1007/BF00806091

SANTILLAN MK, PELHAM CJ, KETSAWATSOMKRON P, SANTILLAN DA, DAVIS DR, DEVOR EJ, GIBSONCORLEY KN, SCROGGINS SM, GROBE JL, YANG B, HUNTER SK, SIGMUND CD: Pregnant mice lacking indoleamine 2,3-dioxygenase exhibit preeclampsia phenotypes. Physiol Rep 3: 1-9, 2015. https://doi.org/10.14814/phy2.12257

SCHROCKSNADEL H, BAIER-BITTERLICH G, DAPUNT O, WACHTER H, FUCHS D: Decreased plasma tryptophan in pregnancy. Obstet Gynecol 88: 47-50, 1996. https://doi.org/10.1016/0029-7844(96)00084-1

STONE TW, STOY N, DARLINGTON LG: An expanding range of targets for kynurenine metabolites of tryptophan. Trends Pharmacol Sci 34: 136-143, 2013. https://doi.org/10.1016/j.tips.2012.09.006

SUZUKI S, TONE S, TAKIKAWA O, KUBO T, KOHNO I, MINATOGAWA Y: Expression of indoleamine 2,3-dioxygenase and tryptophan 2,3-dioxygenase in early concepti. Biochem J 355: 425-429, 2001. https://doi.org/10.1042/bj3550425 
VÁRNAGY Á, BÓDIS J, KOVÁCS GL, SULYOK E, RAUH M, RASCHER W: Metabolic hormones in follicular fluid in women undergoing in vitro fertilization J Reprod Med: 58: 305-311, 2013.

VÁRNAGY Á, KÖSZEGI T, GYÖRGYI E, SULYOK E, PRÉMUSZ V, BÓDIS J: Levels of total antioxidant capacity and 8-hydroxy-2'-deoxyguanosine of serum and follicular fluid in women undergoing in vitro fertilization: Focusing on endometriosis. Hum Fertil: 1-9, 2018.

VESELA J, REHAK P, MIHALIK J, CZIKKOVA S, POKORNY J, KOPPEL J: Expression of serotonin receptors in mouse oocytes and preimplantation embryos. Physiol Res 52: 223-228, 2003.

WEISS G, DIEZ-RUIZ A, MURR C, THEUR I, FUCHS D: Tryptophan metabolites as scavengers of reactive oxygen and chlorine species. Pteridines. 13: 140-143, 2002. https://doi.org/10.1515/pteridines.2002.13.4.140

WICHERS MC, KOEK GH, ROBAEYS G, VERKERK R, SCHARPE S, MAES M: IDO and interferon-alpha-induced depressive symptoms: a shift in hypothesis from tryptophan depletion to neurotoxicity. Mol Psychiatry 10: 538-544, 2005. https://doi.org/10.1038/sj.mp.4001600

WOLF H, BROWN RR, PRICE JM, MADSEN PO: Studies on tryptophan metabolism in male subjects treated with female sex hormones. J Clin Endocrinol Metab 31: 397-408, 1970. https://doi.org/10.1210/jcem-31-4-397

WOLF H, Studies on tryptophan metabolism in man. Scand J Clin Lab Invest 136: 1-186, 1974.

XU K, LIU G, FU C: The tryptophan pathway targeting antioxidant capacity in the placenta. Oxid Med Cell Longev 2018: 1-8, 2018. https://doi.org/10.1155/2018/1054797

YUE CY, ZHANG B YING CM: Elevated serum level of IL-35 associated with the maintenance of maternal-fetal immune tolerance in normal pregnancy. PLoS One 10: e0128219, 2015. https://doi.org/10.1371/journal.pone.0128219 